\title{
ANALYTICAL SEISMIC QUALIFICATION OF EXHAUST SYSTEM ON DIESEL GENSET
}

\author{
Bhavik Bhesaniya $^{1}$, Naveen Agrawal ${ }^{2}$

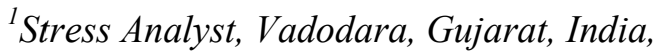 \\ bhavik.bhesaniya@gmail.com \\ ${ }^{2}$ Senior Stress Analyst, Vadodara, Gujarat, India, \\ agrawal.naveen@gmail.com
}

\begin{abstract}
Usually experimental and numerical studies are conducted on engine components for seismic qualification. Experimental method requires lots of iterations and good amount of money to execute the tests. On the other hand, Numerical method is now used rapidly to avoid additional expenses and rework. Numerical method has already demonstrated its effectiveness in improving seismic performance of engine components. Both approaches have been successfully implemented in numerous cases worldwide. But the higher cost is the main drawback of both the method over analytical qualification. The primary objective of the present study is to develop analytical validation approach for simplified numerical model of genset exhaust system used in industry. The present paper aims to fill the gap between time consuming experimental approach and costly numerical approach by simplified analytical approach for seismic qualification. Frequent design modification can be validated economically through analytical approach as well. An integrated diesel engine, a generator and various ancillary devices is referred to as a "generating set" or a "genset" for short. An Engine consists a set of manifold and pipes, which is considered as critical set for analytical qualification. An Engine exhaust system is usually piping system, used to guide reaction exhaust gases away from a controlled combustion, inside an engine. The entire system conveys burnt gases from the exhaust ports and delivers to the turbocharger through exhaust manifold. This paper highlights analytical seismic qualification of the exhaust manifold supplied with Diesel engine. The seismic functions of these components are structural integrity and position retention. Along with structure components, bolts have also been checked under pressure, dead weight and seismic loads together at service temperature.
\end{abstract}

Keywords: Seismic Qualification, Exhaust Manifold, Analytical Validation, ANSI/AISC, Diesel Genset

\section{INTRODUCTION}

Now a days many organisations target customer's needs by experiencing minimum pain of expensive recalls, costly product rework, and unexpected delays in product releases. It is achieved through an effective product design verification and validation process either by digital or physical means during product development phase. Verification and validation is the process of ensuring whether design meets the desired standard, means "you built it right" and "you built the right thing." Question raises about the time consumption and cost involved either in digital means or in physical means which are most important factors in current competitive market. To reduce both of them it is proposed to conduct analytical validation which is economical and more conservative approach.

This paper highlights the proposed analytical validation on exhaust system components for seismic qualification. Analytical validation starts from defining simple representation of component system, creation of free-body diagram, and identification of right engineering principles

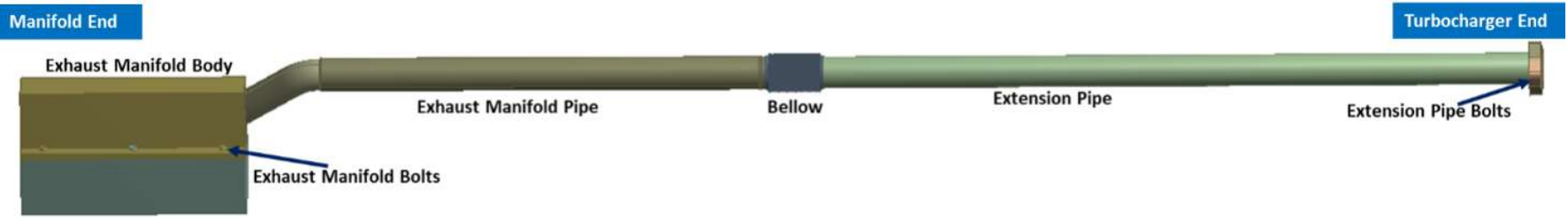

Figure 1: Simplified Exhaust Manifold Geometry

to the assessment of component. It involves basic engineering principles and fundamentals to apply which in turn convert the problem in more conservative environment.

Considered exhaust system component is an integral part of an engine which conducts the gases from the exhaust ports and delivers to the turbocharger. An Engine exhaust system is usually piping system, used to guide reaction exhaust gases away from a controlled combustion, inside an engine. The seismic functions of these components are structural integrity and position retention. Along with structure components, bolts have also been checked under pressure, dead weight and seismic loads together at service temperature. 
Typical Exhaust system comprises exhaust Manifold body and extension pipe [Figure 1]. This pipe also mechanically divided by the bellows. Bellows are provided on exhaust manifold system to accommodate thermal expansion of the piping in all directions during Genset operation. Exhaust system components, which considered for seismic qualification, are exhaust manifold body with pipe up to bellow and extended pipe of exhaust manifold from bellow to turbocharger end.

Manifold Pipes are welded to the flange at turbo charger end followed by bolted connection of flange with turbocharger body. Turbocharger body is considerably rigid in comparison to Manifold pipes. Exhaust manifold including exhaust manifold pipes are insulated with blankets to prevent heat transfer from exhaust gases to atmosphere and prevent burn injuries to people. Approximated blanket weight $(10 \%)$ is added in total component weight for mass calculation.

\section{ANALYTICAL APPROACH}

Each component should withstand during and after seismic loading and should demonstrate the structural integrity and position retention functionalities. Analytical approach is used to seismically qualify following components as below:

$>$ Exhaust Manifold Body

$>$ Exhaust Manifold Bolt

$>$ Exhaust Manifold Pipe

$>$ Bellow

$>$ Extension Pipe

$>$ Extension Pipe Bolts

\subsection{Exhaust Manifold Body}

The Manifold body [Figure 2] is robustly designed to permit the Exhaust gas from engine cylinder to turbocharger through exhaust pipe. The Manifold body is very rigid, stub in size and in operation in field from many years, so it can be considered to be seismically qualified which will retain its functionalities during and after seismic events.

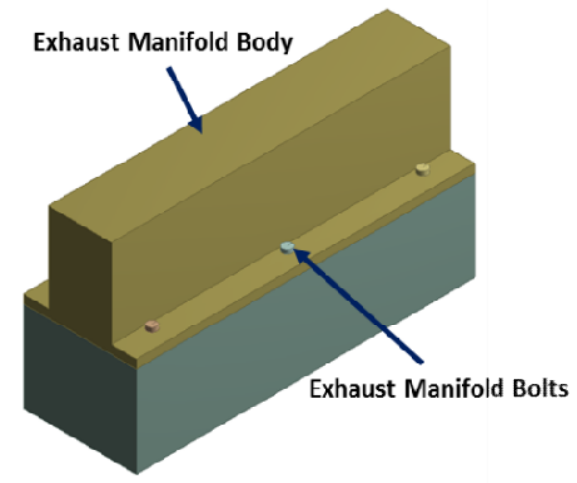

Figure 2: Exhaust Manifold Body and Bolts

\section{Exhaust Manifold Bolt}

The Manifold body is attached to the exhaust belts using six 9/16" fitted bolts [Figure 2].

Bolts will experience static loading due to mass of connected pipe up to bellow (bellow ends are considered as free ends) and the mass of Manifold. The Manifold body with its connected pipe is modelled as a cantilever beam. Force diagram is illustrated in [Figure 5] for forces applied on manifold bolts.

Combined operational and seismic loads on the bolts at the exhaust belt location are calculated and checked to ensure that the bolt Shear-Tension Interaction Formula (STIF) [Equation 1] from Ref [1] is met.

$\mathrm{STIF}=\mathrm{f}_{\mathrm{t}}^{2} / \mathrm{F}_{\mathrm{t}}^{2}+\mathrm{f}_{\mathrm{v}}^{2} / \mathrm{F}_{\mathrm{v}}^{2} \leq 1$ Equation 1

Where,

$\mathrm{f}_{\mathrm{t}}=$ Tensile Stress

$\mathrm{f}_{\mathrm{V}}=$ Tensile Stress

$\mathrm{F}_{\mathrm{t}}=$ Allowable tensile stress in absence of shear stress

$\mathrm{F}_{\mathrm{V}}=\quad$ Allowable shear stress in absence of tensile stress

The tensile load on the bolt will be checked against the allowable load for thread pull out from the exhaust belt. Plus, the bending stress on the bolt, as a cantilever beam, due to seismic mass loading will be calculated.

\subsection{Exhaust Manifold Pipe}

There are two manifold pipes which are separated by bellow. Bellow is considered as free end for each pipe. Either of them can be considered for analytical qualification because both of them are made of same material and same size. Since size of exhaust manifold pipe [Figure 3] at exhaust manifold body side is shorter in length as compare to extension pipe, it would be considered to be seismically qualified which will retain its functionalities during and after seismic events.

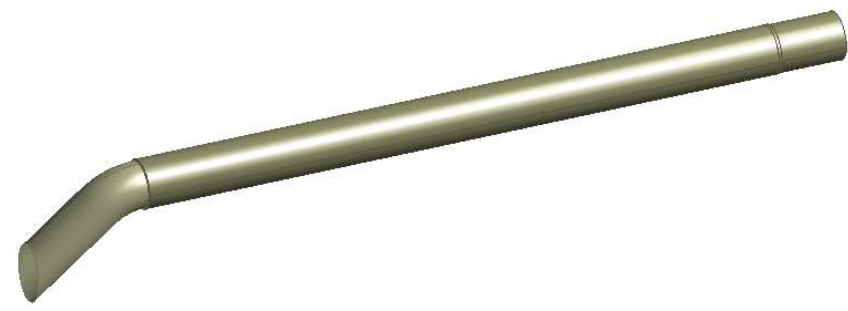

Figure 3: Exhaust Manifold Pipe

\subsection{Bellow}

Bellow [Figure 4] is used to provide relief in case of thermal expansion and absorb loads in case of vibration. Bellow is in operation in field from many years, so it can be considered to be seismically qualified which will retain its functionalities during and after seismic events.

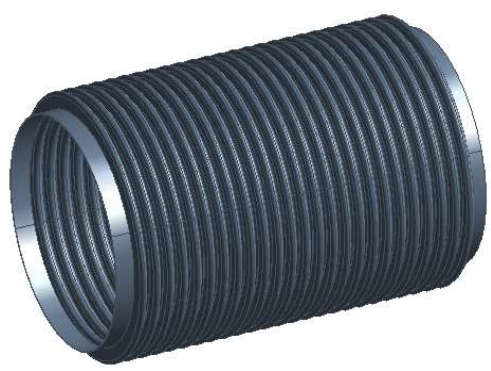

Figure 4: Bellow 

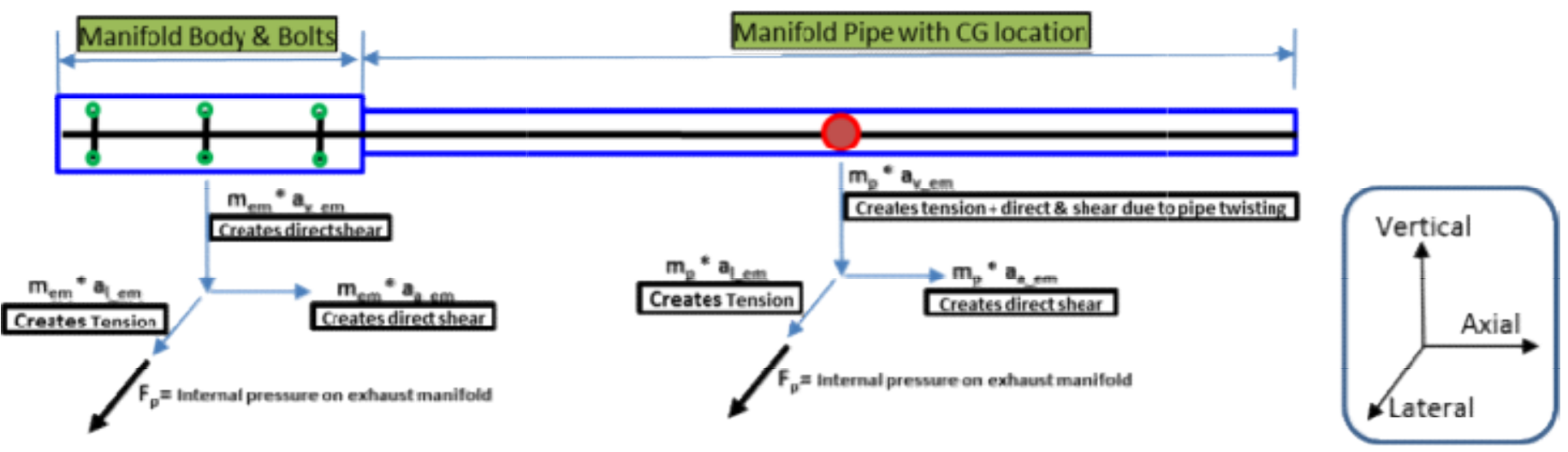

Figure 5: Force Diagram for Exhaust Manifold Bolts

\subsection{Extension Pipe}

Extension Pipe [Figure 6] is having 4.19" ID x 4.5" OD and is made of DOM MT 1020-26. This pipe is connected to the flange by welded joint followed by bolted connection with turbocharger body using four $1 / 2$ " bolts while it is considered as free at other side due to bellow connection. Combined operational and seismic loads on Pipe including $10 \%$ of blanket weight is applied and checked to ensure that bending stresses are within the allowable limits as given below.

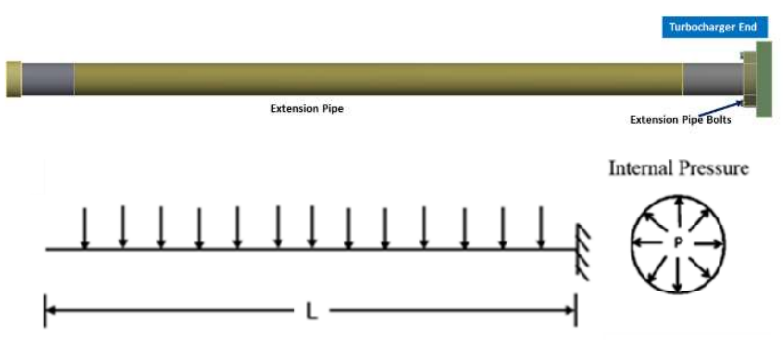

Figure 4: Extension Pipe and Bolts

\subsection{Extension Pipe Bolt}

Extension Pipe is welded to flanges at turbocharger end which is attached to the turbo charger through 2 bolts of $1 / 2$ " size [Figure 6]. The bolts are considered for the analytical qualification where Pipe is considered as a cantilever beam. Bolts are checked whether Shear-Tension Interaction Formula (STIF) [Equation 1] is met.

\section{ANALYTICAL CALCULATIONS PARAMETERS}

Certain input parameters are required to perform the analytical calculation which includes details on dimensions, material properties, accelerations, masses and allowable stress. Those are listed in respective sections below:

\subsection{Dimensions}

The basic dimensions of the exhaust system components are summarized in Table 1.

Table 1: Dimensions of the exhaust system components

\begin{tabular}{|c|c|c|c|}
\hline Component & Description & Value & Nomenclature \\
\hline \multirow{3}{*}{ Manifold Body } & Outer Diameter & $4.7 \mathrm{in}$ & $\mathrm{OD}_{\mathrm{em}}$ \\
\hline & Volume of Manifold including Pipe & 433.14 in $^{3}$ & $\mathrm{~V}_{\mathrm{em} \mathrm{p} \mathrm{b}}$ \\
\hline & Thickness & 0.3 in & $t_{\mathrm{em}}$ \\
\hline \multirow{6}{*}{ Manifold bolt } & Diameter & $0.562 \mathrm{in}$ & $\mathrm{D}_{\text {bolt em }}$ \\
\hline & Tensile Area & $0.1820 \mathrm{in}^{2}$ & $\mathrm{~A}_{\text {bolt em }}$ \\
\hline & No of bolts per manifold & 6 & $\mathrm{~N}_{\text {bolt em }}$ \\
\hline & Tensile Area & $1.092 \mathrm{in}^{2}$ & $\mathrm{Al}_{\text {bolt em }}$ \\
\hline & Axial distance from end bolts of Manifold to C.G of Pipe & 43 in & $\mathrm{L}_{\mathrm{em} \mathrm{ptb}}$ \\
\hline & Center to Center Distance between Manifold inlet \& Manifold bolt & $3.375 \mathrm{in}$ & $\mathrm{d}_{\mathrm{cc} \text { em bolt }}$ \\
\hline \multirow{3}{*}{ Manifold Pipe } & Outer Diameter & 4.5 in & $\mathrm{OD}_{\mathrm{p}}$ \\
\hline & Length & 73.125 in & $\mathrm{ID}_{\mathrm{p}}$ \\
\hline & Inner Diameter & 4.25 in & $\mathrm{L}_{\mathrm{p}}$ \\
\hline \multirow{5}{*}{ Extension Pipe } & Outer Diameter & 4.375 in & $\mathrm{OD}_{\text {pipe }}$ \\
\hline & Length & 97 in & $\mathrm{L}_{\text {pipe }}$ \\
\hline & Thickness & 0.0935 in & $t_{\text {pipe }}$ \\
\hline & Inner Diameter & 4.188 in & $\mathrm{ID}_{\text {pipe }}$ \\
\hline & Area & $1.718 \mathrm{in}^{2}$ & $\mathrm{~A}_{\text {pipe }}$ \\
\hline \multirow{3}{*}{ Extension Pipe bolt } & Tensile Area (1/2") & $0.24725 \mathrm{in}^{2}$ & $\mathrm{~A}_{\text {bolt pipe }}$ \\
\hline & Distance between bolt Center to center of Pipe & 3.2 in & $\mathrm{d}_{\mathrm{cc} \text { bolt pipe }}$ \\
\hline & Number of Pipe bolts to flange at turbocharger & 2 & $\mathrm{~N}_{\text {bolt pipe }}$ \\
\hline
\end{tabular}




\subsection{Component Masses}

The components masses are summarized in Table 2 .

Table 2: Mass of components

\begin{tabular}{|l|l|l|}
\hline Component & Value & Nomenclature \\
\hline Manifold Body, Manifold Pipe \& Blankets $(10 \%$ of components) & $123.9 \mathrm{lbm}$ & $\mathrm{m}_{\mathrm{em}}$ \\
\hline $\begin{array}{l}\text { Manifold Pipe \& Blankets } \\
(10 \% \text { of components) }\end{array}$ & $35.93 \mathrm{lbm}$ & $\mathrm{m}_{\mathrm{p}}$ \\
\hline $\begin{array}{l}\text { Extension Pipe \& Blankets } \\
(10 \% \text { of component) }\end{array}$ & $34.89 \mathrm{lbm}$ & $\mathrm{m}_{\text {pipe }}$ \\
\hline
\end{tabular}

\subsection{Materials}

The material properties of the components are summarized in Table 3.

Table 3: Structural steel material properties

\begin{tabular}{|c|c|c|c|c|}
\hline Parts & Material & Property & Value & Reference \\
\hline Exhaust Belt & Cast Iron & Tensile Strength & $35,000 \mathrm{psi}$ & Table 2 of $[[3]]$ \\
\hline Exhaust Manifold & Cast Iron & Density $\left(\rho_{\mathrm{ss}}\right)$ & $0.26 \mathrm{lbm} / \mathrm{in}^{3}$ & Table PRD of [[2]] \\
\hline \multirow{4}{*}{$\begin{array}{l}\text { Manifold } \\
\text { Bolt }\end{array}$} & \multirow{4}{*}{ SAE 4140 HT (9/16") } & Tensile Strength@ RT $^{*}$ & $125,000 \mathrm{psi}$ & \multirow{2}{*}{ Table U of [[2]] } \\
\hline & & Tensile Strength@800F & $108,400 \mathrm{psi}$ & \\
\hline & & Yield Strength@ RT ${ }^{*}$ & $105,000 \mathrm{psi}$ & \multirow{2}{*}{ Table Y1 of [[2]] } \\
\hline & & Yield Strength @ 800F & $73,900 \mathrm{psi}$ & \\
\hline \multirow{6}{*}{ Extension Pipe } & \multirow{6}{*}{ DOM MT 1020-26 } & Yield Strength@ RT $^{*}$ & $60,000 \mathrm{psi}$ & \multirow{2}{*}{ Table Y1 of [[2]] } \\
\hline & & Yield Strength@ 800F & $36,600 \mathrm{psi}$ & \\
\hline & & Tensile Strength @ RT $^{*}$ & $70,000 \mathrm{psi}$ & Toble U of [121] \\
\hline & & Tensile Strength@800F & $64,300 \mathrm{psi}$ & Table U of $[[2]]$ \\
\hline & & Young’s Modulus@RT* & $29,400 \mathrm{ksi}$ & $\begin{array}{ll}\text { Table } & \text { TM-1 }\end{array}$ \\
\hline & & Young’s Modulus@800F & $25,000 \mathrm{ksi}$ & {$[[2]]$} \\
\hline Fu & CA & Tensile Strength@ RT ${ }^{*}$ & $170,000 \mathrm{psi}$ & T \\
\hline Extenston ripe oon & SAE $490(1 / 2)$ & Tensile Strength@800F & $124,000 \mathrm{psi}$ & 1 abie U or $[[2]]$ \\
\hline
\end{tabular}

\section{LOADING DETAILS}

\subsection{Pressure}

Exhaust Pressure of 25 psi is considered for exhaust system component for analytical calculations.

\subsection{Seismic Acceleration}

\subsubsection{Manifold Body \& Manifold Pipe}

These components are attached to exhaust belts which masses are considered in FE analysis of Main skid. Hence
Seismic acceleration loads are extracted from main skid analysis for exhaust belts and corresponding directional values of the response spectrum is used. Standard earth gravity will be added to the vertical direction. The squared value of each direction will be added together and then the square root will be taken to come up with the absolute magnitude of acceleration as shown in Table 4.To simplify the analysis, the absolute magnitude of acceleration will be used for all acceleration load calculations.

Table 4: Acceleration for Manifold Body \& Manifold Pipe

\begin{tabular}{|l|l|l|}
\hline Direction & All Components & Nomenclature \\
\hline Vertical (parallel to piston axis) & $1.32 \mathrm{~g}$ & $\mathrm{a}_{\mathrm{v} \_\mathrm{em}}$ \\
\hline Lateral (perpendicular to axis of the crankshaft) & $0.52 \mathrm{~g}$ & $\mathrm{a}_{1 \_\mathrm{em}}$ \\
\hline Axial (parallel to crankshaft axis) & $0.58 \mathrm{~g}$ & $\mathrm{a}_{\mathrm{a} \_\mathrm{em}}$ \\
\hline Gravity & $1 \mathrm{~g}$ & $\mathrm{a}_{\mathrm{g} \_\mathrm{em}}$ \\
\hline Combined Vertical (including gravity) and Lateral seismic acceleration & $2.378 \mathrm{~g}$ & $\mathrm{a}_{\mathrm{c} \_\mathrm{em}}$ \\
\hline Combined Axial and Lateral seismic acceleration & $0.779 \mathrm{~g}$ & $\mathrm{a}_{1 \_ \text {a } \_\mathrm{em}}$ \\
\hline
\end{tabular}




\subsubsection{Extension Pipe}

This component is attached to turbocharger which masses are considered in FE analysis of Main skid. Hence Seismic acceleration loads are extracted from main skid analysis for turbocharger and corresponding directional values of the response spectrum is used. Standard earth gravity will be added to the vertical direction. The squared value of each direction will be added together and then the square root will be taken to come up with the absolute magnitude of acceleration as shown in Table 5. To simplify the analysis, the absolute magnitude of acceleration will be used for all acceleration load calculations.

Table 5: Acceleration for Extension Pipe

\begin{tabular}{|l|l|l|}
\hline Direction & All Components & Nomenclature \\
\hline $\begin{array}{l}\text { Vertical } \\
\text { (parallel to piston axis) }\end{array}$ & $2.28 \mathrm{~g}$ & $\mathrm{a}_{\mathrm{v} \_\mathrm{p}}$ \\
\hline $\begin{array}{l}\text { Lateral } \\
\text { (perpendicular to axis of the crankshaft) }\end{array}$ & $1.12 \mathrm{~g}$ & $\mathrm{a}_{1 \_\mathrm{p}}$ \\
\hline $\begin{array}{l}\text { Axial } \\
\text { (parallel to crankshaft axis) }\end{array}$ & $1.9 \mathrm{~g}$ & $\mathrm{a}_{\mathrm{a} \_\mathrm{p}}$ \\
\hline Gravity & $1 \mathrm{~g}$ & $\mathrm{a}_{\mathrm{g} \_\mathrm{p}}$ \\
\hline Combined Vertical (including gravity) and Lateral seismic acceleration & $3.466 \mathrm{~g}$ & $\mathrm{a}_{\mathrm{ss} \_\_ \text {vl }}$ \\
\hline
\end{tabular}

\section{ALLOWABLE STRESS}

Extension Pipe stress from pressure, dead weight and seismic loads will be conservatively compared against lowest of the $1 / 3$ th ultimate or $2 / 3$ rd the yield strength of the material [Ref. section 302.3.2] of [4]. The allowable stresses are summarized in Table 6. To account thermal effect on entire assembly, Seismic calculations are done with temperature dependent material properties at $800^{\circ} \mathrm{F}$.

Table 1: Structural steel allowable stress

\begin{tabular}{|c|c|c|c|c|c|}
\hline Material & $\begin{array}{c}\text { Ultimate } \\
\text { Tensile } \\
\text { Strength (psi) }\end{array}$ & $\begin{array}{l}\text { Yield } \\
\text { Strength } \\
\text { (psi) }\end{array}$ & $\begin{array}{l}\text { 1/3 Ultimate } \\
\text { (psi) @ } 800 \mathrm{~F}\end{array}$ & $\begin{array}{c}\text { 2/3 Yield } \\
\text { (psi)@ } @ 800 \mathrm{~F}\end{array}$ & $\begin{array}{l}\text { Allowable Stress } \\
\text { (psi)@ } @ 800 \mathrm{~F}\end{array}$ \\
\hline $\begin{array}{l}\text { DOM } \\
\text { MT }\end{array}$ & $70,000 @ \mathrm{RT}^{*}$ & $60,000 @ \mathrm{RT}^{*}$ & \multirow{2}{*}{21,433} & \multirow{2}{*}{24,400} & \multirow{2}{*}{21,433} \\
\hline $1020-26$ & 64,300@800F & 36,600@800F & & & \\
\hline
\end{tabular}

\section{RESULT DISCUSSION}

The Exhaust Manifold components including Manifold Pipe, Extension Pipe \& it's mounting bolts are analytically analysed to ensure that the Exhaust Manifold components will continue to function and will remain structurally sound during and after a seismic events. For each component, analytical and FEA results are listed with detailed explanation.

\subsection{Exhaust Manifold Bolt}

6 bolts of each exhaust manifold carry the entire operating load coming from the respective exhaust manifold and its pipe. Location and its magnitude is as under, which is well aligned with the analytical results. Formulae for stress, strain, beam shear and bending are considered from Ref [5,6,7,8\&9] and shown in Mathcad document.
Case\#1: Shear Stress due to Exhaust Manifold

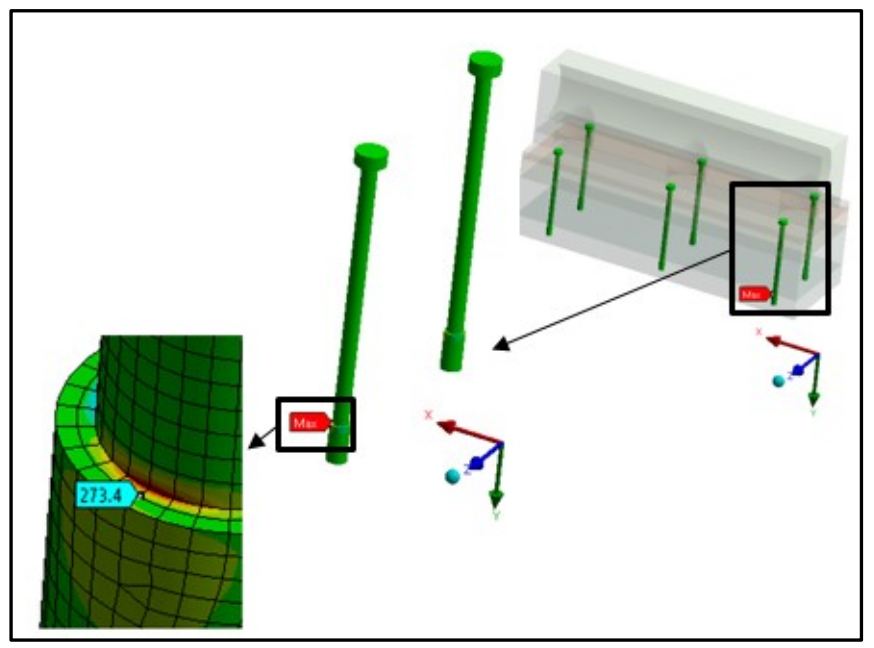


Force due to weight of Exhaust Manifold Body and Manifold Pipe; Combined volume is taken to figure out complete mass of Exhaust Manifold Body and Manifold Pipe

$F_{\text {bolt_em_1 }}:=m_{e m} \cdot a_{c \_e m}=294.528$ lbf

Shear Force on bolts due to Exhaust Manifold Body

$\sigma_{\text {bolt_shear_manifold }}:=\frac{F_{\text {bolt_em_1 }}}{A 1_{\text {bolt_em }}}=269.714$ psi

Figure 7: Exhaust Manifold Bolts: Case\#1 - FEA \& Analytical results

Case\#2: Shear Stress due to Manifold Pipe

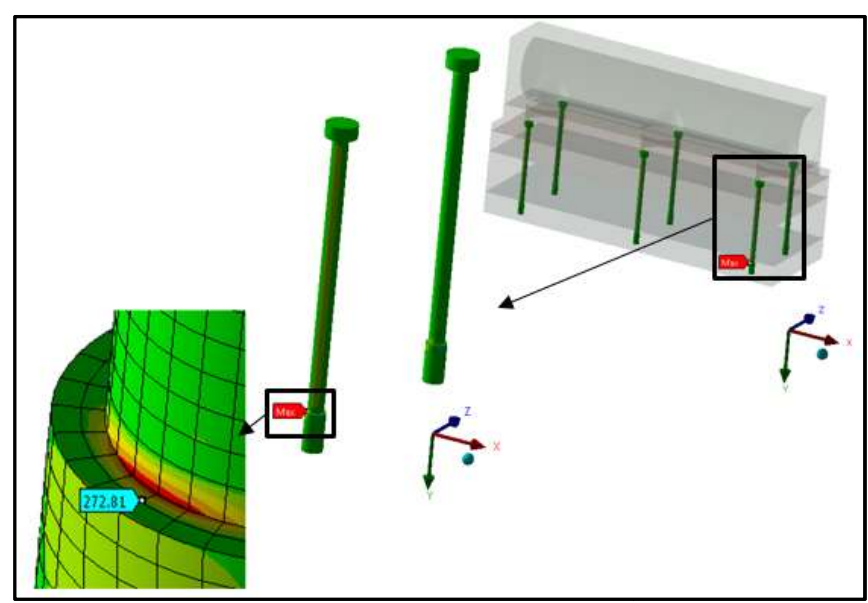

Twisting Moment on bolts due to Manifold Pipe in vertical direction.

$T_{\text {bolt_em }}:=\frac{\left(m_{p} \cdot a_{v \_e m}\right)}{L_{\text {em_ptb }}} \cdot \frac{L_{\text {em_ptb }}{ }^{2}}{2}=1002 \mathrm{lbf} \cdot \mathrm{in}$

Shear Force on bolts due to pipe

$F_{\text {bolt_em_2 }}:=\frac{T_{\text {bolt_em }}}{d_{c c \_e m \_b o l t}}=297$ lbf

Shear Stress on bolts

$\sigma_{\text {bolt_shear_pipe }}:=\frac{F_{\text {bolt_em_} \_2}}{A 1_{\text {bolt_em }}}=271.96$ psi

Figure 8: Exhaust Manifold Bolts: Case\#2 - FEA \& Analytical results
Case\#3: Bending Stress due to combine assembly

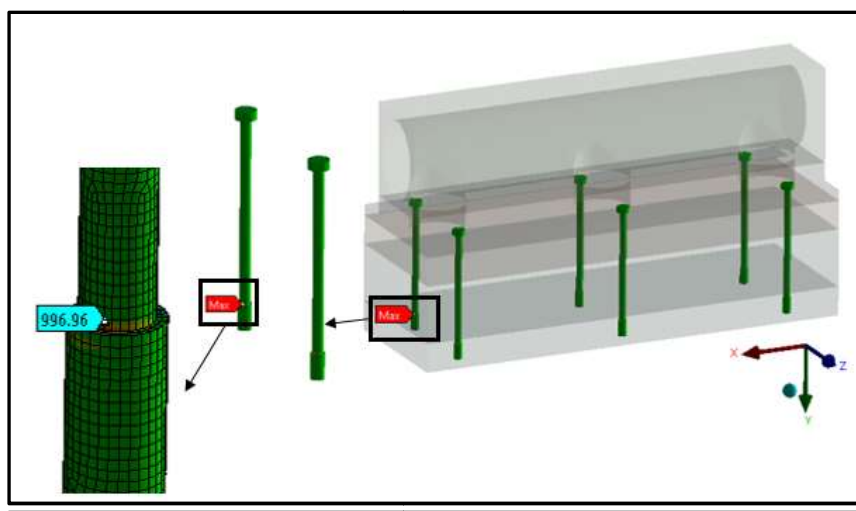

Total Tensile Forces on bolts due to moment on Manifold Pipe, due to internal pressure and due to forces in engine lateral and axial directions.

$P_{b o l t}:=p_{e x h} \cdot\left(0.25 \cdot \pi \cdot\left(1.25 \cdot O D_{e m}\right)^{2}\right)=677.713 l b f$

$F_{\text {bolt_tensile }}:=F_{\text {bolt_em_2 }}+P_{\text {bolt }}+m_{\text {em }} \cdot a_{l \_a \_e m}=1071.19$ lbf

Total Tensile stress on bolts

$\sigma_{\text {bolt_tensile }}:=\frac{F_{\text {bolt_tensile }}}{A 1_{\text {bolt_em }}}=980.944$ psi

Figure 9: Exhaust Manifold Bolts: Case\#3 - FEA \& Analytical result

\subsection{Extension Pipe}

Extension Pipe is also validated as it is having longest length among all pipes. Extension pipe is simulated as a cantilever case with turbo charger end fixed and manifold end is free from bellow location. Results are found as below.

Case\#1: Tensile Stress due to Vertical Acceleration
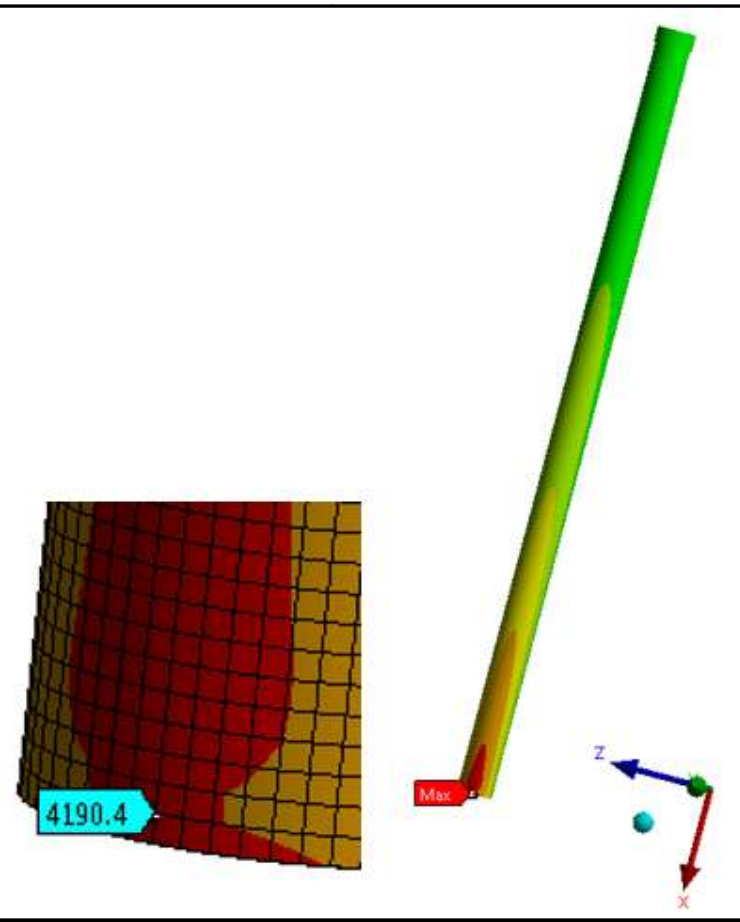
Combined vertical \& lateral acceleration on

Extension Pipe for bending moment calculation

$a_{s s e_{-} p_{-} v l}:=\sqrt{\left(a_{l_{-} p}\right)^{2}+\left(a_{g_{-} p}+a_{v_{-} p}\right)^{2}}=3.466 \mathrm{~g}$

Moment on Extension Pipe

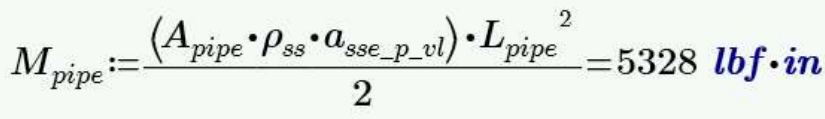

Inertia of Extension Pipe

$I_{\text {pipe }}:=\frac{\pi}{64} \cdot\left(O D_{\text {pipe }}{ }^{4}-I D_{\text {pipe }}{ }^{4}\right)=2.883 \mathrm{in}^{4}$

Tensile stress due to Vertical \& Lateral force

$\sigma_{T_{-} v l}:=\left(\frac{M_{\text {pipe }} \cdot \frac{O D_{\text {pipe }}}{2}}{I_{\text {pipe }}}\right)=4042.4 \mathrm{psi}$

Figure 10: Extension Pipe: Case\#1 - FEA $\&$ Analytical results

Case\#2: Tensile Stress due to Axial Acceleration
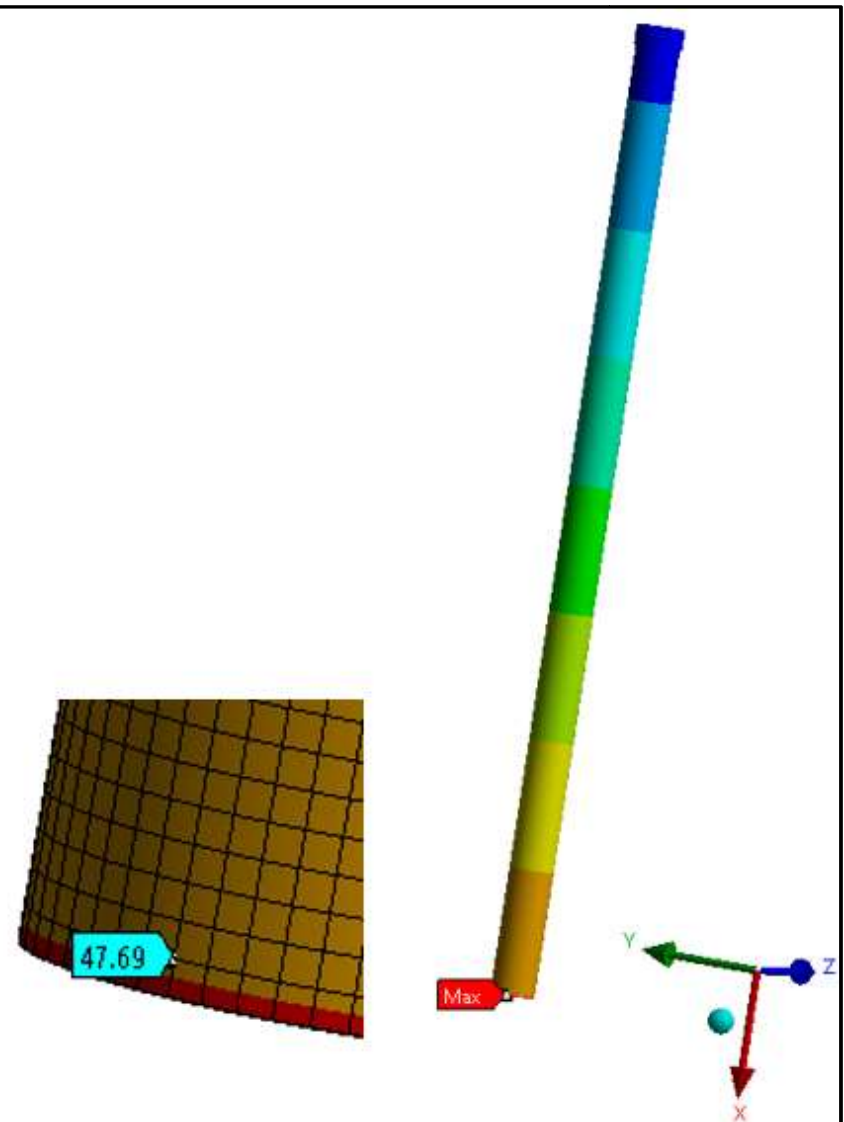

Tensile stress due to Axial force

$\sigma_{T \_a}:=\frac{m_{\text {pipe }} \cdot a_{a \_p}}{A_{\text {pipe }}}=52.691 \mathrm{psi}$

Figure 11: Extension Pipe: Case\#2 - FEA

$\&$ Analytical results

Case\#3: Axial Stress due to Internal Pressure

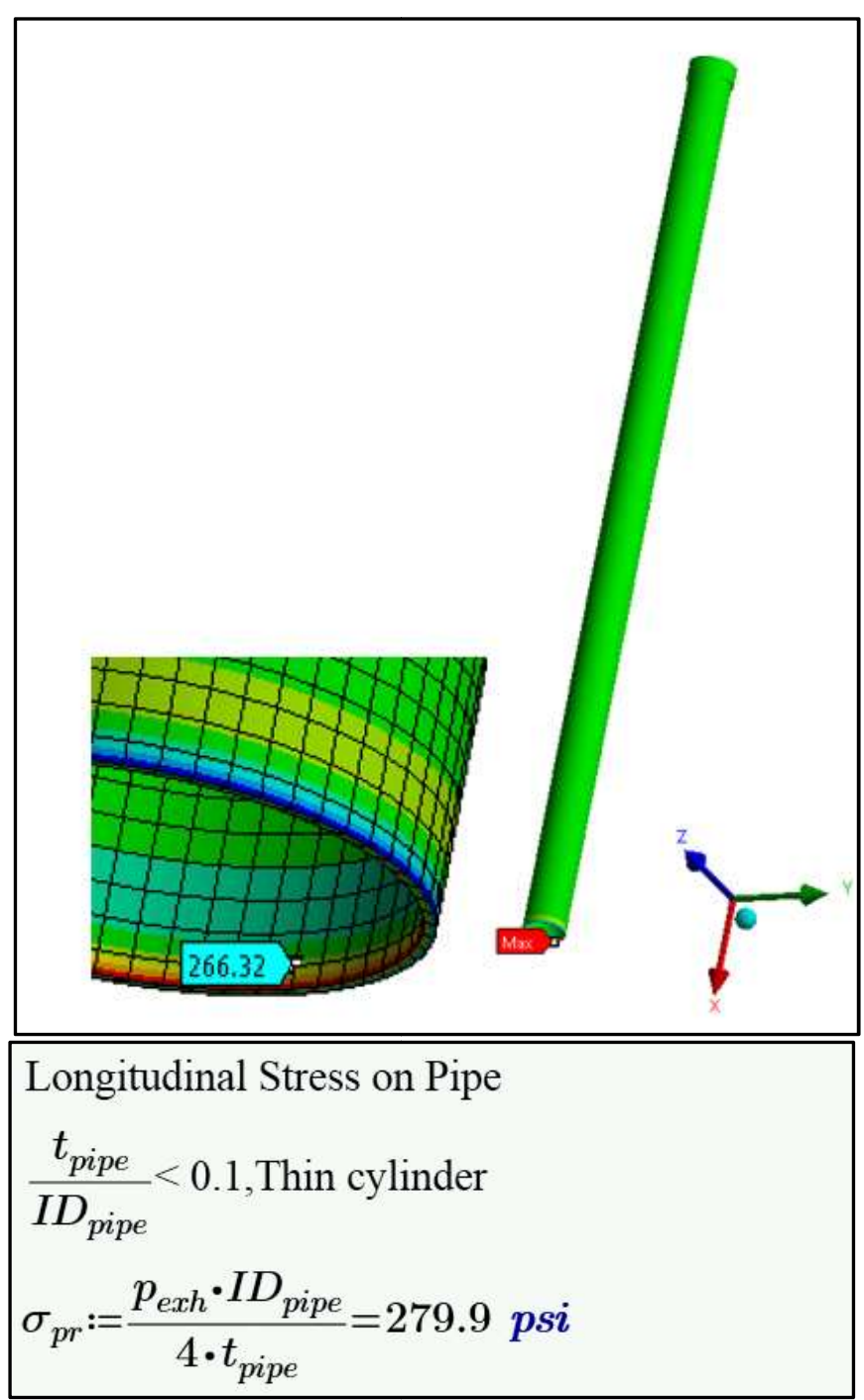

Figure 12: Extension Pipe: Case\#3 - FEA \& Analytical results

\subsection{Extension Pipe Bolts}

Three bolts from each pipe end take the upcoming load from the attached piping. 
Case\#1: For Lateral Acceleration

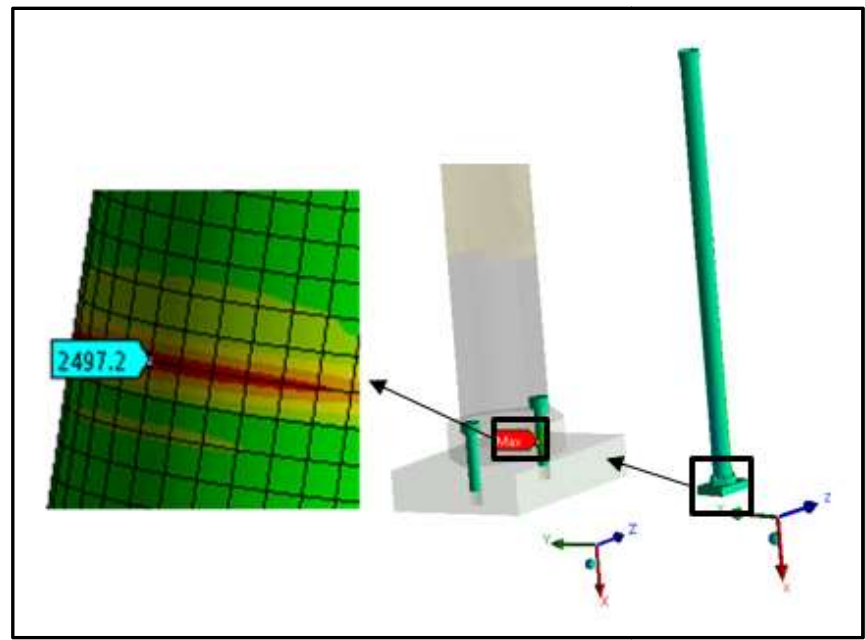

Lateral force on Extension Pipe

$F_{l}:=m_{\text {pipe }} \cdot a_{l_{-} p}=39.062 \mathrm{lbf}$

Moment on Extension Pipe due to Lateral force

$M_{T_{-} l}:=F_{l} \cdot L_{\text {pipe }}=3787.7 \mathrm{lbf} \cdot$ in

Lateral force on bolt

$F_{\text {bolt_pipe }}:=\frac{M_{T_{-} l}}{d_{\text {cc_bolt_pipe }} \cdot N_{\text {bolt_pipe }}}=647.2$ lbf

Tensile stress on bolt due to Lateral force

$\sigma_{T_{-} l}:=\frac{F_{\text {bolt_pipe }}}{A_{\text {bolt_pipe }}}=2617.6 \mathrm{psi}$

Figure 13: Extension Pipe Bolts: Case\#1 - FEA \& Analytical results

Case\#2: For Axial Acceleration

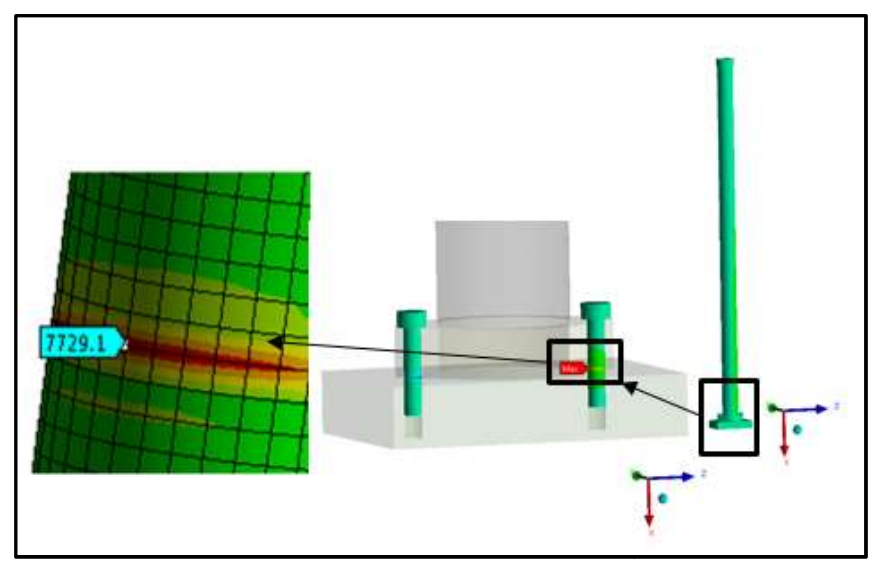

Vertical force on Extension Pipe

$F_{v}:=m_{\text {pipe }} \cdot\left(a_{g_{-} p}+a_{v_{-} p}\right)=114.4 \mathrm{lbf}$

Moment on Extension Pipe due to Vertical force

$M_{T_{-} v}:=F_{v} \cdot L_{\text {pipe }}=11092.4 \mathrm{lbf} \cdot \boldsymbol{i n}$

Distance from pipe center line to top of the flange (upward direction)

$d_{c c \_b o l t \_p i p e \_v}:=2.813$ in

Tensile force shared by 3 bolts

$F_{\text {bolt_pipe_v }}:=\frac{M_{T_{-} v}}{d_{c c \_b o l t \_p i p e_{-} v} \cdot N_{\text {bolt_pipe }}}=1971.6 \mathrm{lbf}$

Tensile stress on bolt due to Vertical force

$\sigma_{T_{-} v}:=\frac{F_{\text {bolt_pipe_v }}}{A_{\text {bolt_pipe }}}=7974.3 \mathrm{psi}$

Figure 14: Extension Pipe Bolts: Case\#2 - FEA \& Analytical results

Case\#3: For Vertical Acceleration

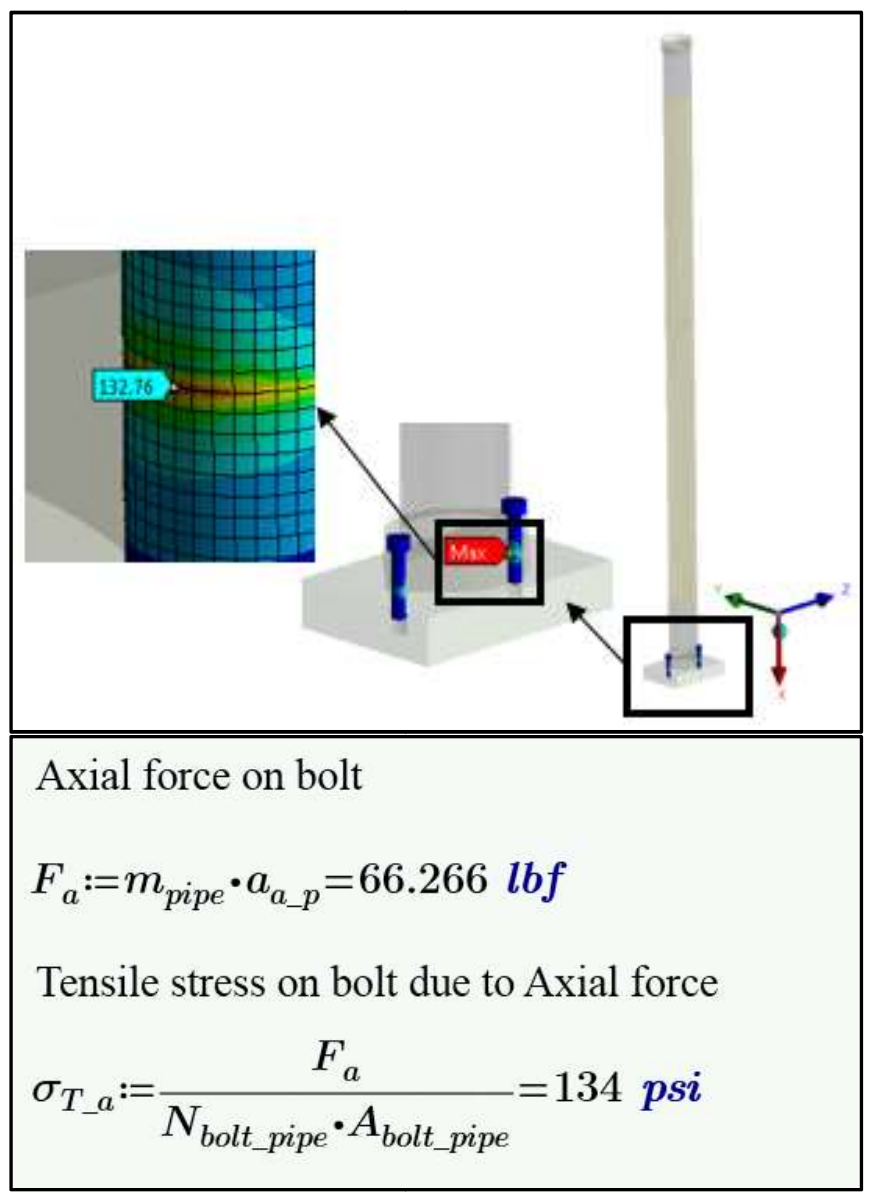

Figure 15: Extension Pipe Bolts: Case\#3 - FEA \& Analytical results 


\section{RESULT SUMMARY}

Table 7 summarizes the resulting tensile, shear and the allowable stresses.

Table 7: Result Summery

\begin{tabular}{|l|l|l|l|l|}
\hline \multirow{2}{*}{ Parts } & Stress & $\begin{array}{l}\text { Analytical } \\
\text { Results (psi) }\end{array}$ & $\begin{array}{l}\text { FEA } \\
\text { Results (psi) }\end{array}$ & \% Variation \\
\hline \multirow{4}{*}{$\begin{array}{l}\text { Manifold } \\
\text { bolt }\end{array}$} & Case\#1: Shear Stress due to Exhaust Manifold & 269.71 & 273.4 & 1.4 \\
\cline { 2 - 6 } & Case\#2: Shear Stress due to Manifold Pipe & 276.7 & 272.81 & -1.4 \\
\cline { 2 - 6 } & Case\#3: Bending Stress due to combine assembly & 985.7 & 997 & 1.2 \\
\hline \multirow{4}{*}{\begin{tabular}{l} 
Pipe \\
\cline { 2 - 5 }
\end{tabular}} & Case\#1: Tensile Stress due to Vertical Acceleration & 4045.3 & 4190.4 & 3.6 \\
\cline { 2 - 6 } & Case\#2: Tensile Stress due to Axial Acceleration & 52.71 & 47.69 & -9.5 \\
\cline { 2 - 6 } & Case\#3: Axial Stress due to Internal Pressure & 279.9 & 266.32 & -4.9 \\
\cline { 2 - 6 } & Case\#1: For Lateral Acceleration & 2395.3 & 2497.2 & 4.3 \\
\cline { 2 - 6 } & Case\#2: For Axial Acceleration & 134 & 732.76 & -0.9 \\
\cline { 2 - 5 } & Case\#3: For Vertical Acceleration & 7482.6 & 7729.1 & 3.3 \\
\hline
\end{tabular}

\section{CONCLUSION}

Results summarised in Table 7 indicate that analytical results are close to FEA results and maximum variation is seen as $9.5 \%$ for a single case. All other cases are showing variation less than $5 \%$. Since FEA results are acceptable with maximum $10 \%$ variation, hence it can be concluded that analytical results are well matching with FEA results and acceptable for further assessment.

Based on above results and conclusion, it can also be stated that analytical approach is most suitable and economical method to validate the system or component with low cost and in less time.

\section{ACKNOWLEDGMENTS}

The author is also grateful to all colleagues who supported directly indirectly on my paper work.

\section{REFERENCES}

[1]. AISC N690-1994, (ANSI/AISC) American Institute for Steel Construction, Specification for Design, Fabrication, and Erection of Safety-Related Steel Structures for Nuclear Facilities, with Supplement 2 dated 06 Oct 04.

[2]. ASME Boiler and Pressure Vessel Code Section II Part D "Properties (Customary)", 2013.

[3]. ASTM A48/A48M-03 Standard Specification for Grey Iron Castings.

[4]. ASME Code for Process Piping B31, Section 31.3, 2004.

[5]. "Roark's Formulas for Stress and Strain", 7th Edition, by Roark, Young \& Budynas, published by McGrawHill.

[6]. Beam Design Formulas with Shear and Moment Diagrams, Design AID No.6, American Forest \& Paper Association.

[7]. Table 8-6 of "Mechanical Engineering Design", 5th
Edition, Shigley and Mischke, McGraw Hill Inc., 1989.

[8]. "Machinery's Handbook", 25th edition, Industrial Press Inc., 1996.

[9]. "Mechanical Engineering Reference Manual for the PE Exam", 11th Edition, Professional Publications Inc., 2001 